Dossier: V Simposio Internacional y IX Nacional sobre Derechos de la Niñez y la Adolescencia

\title{
Dossier: V Simposio Internacional y IX Nacional sobre Derechos de la Niñez y la Adolescencia
}

La edición número 41 de la Revista Estudios incluye un dossier del V Simposio Internacional y IX Nacional sobre Derechos de la Niñez y la Adolescencia, organizado por el Programa Interdisciplinario de Estudios y Acción Social de Derechos de la Niñez y la Adolescencia (Programa PRIDENA) de la Universidad de Costa Rica. La actividad internacional fue realizada en colaboración con distintas unidades académicas de la Universidad de Costa Rica, instituciones públicas costarricenses, organizaciones no gubernamentales y organismos internacionales.

El evento fue realizado en setiembre del año 2019 bajo el titulo Desigualdades, abordajes y experiencias en el escenario del Desarrollo Sostenible. El simposio permitió la asistencia y discusión de los distintos actores de la política pública de niñez y adolescencia de América Latina y el Caribe. El total de asistentes fue cerca de 200. De manera presencial participaron representantes de 8 países de la región, Colombia, Argentina, Perú, Guatemala, México, Chile Uruguay y Costa Rica. En el presente número de la Revista Estudios se mostrará a partir de 7 artículos, una parte de las reflexiones que se llevaron a cabo en este valioso y sistemático evento internacional.

El primero de los artículos es el elaborado por las autoras Jiménez y Carmona, quienes presenta la experiencia del programa Aulas de Escucha como modelo de salud mental comunitario para jóvenes en situaciones de vulnerabilidad. Las autoras a través de su texto muestran la metodología del programa, así como sus principales experiencias desde el momento de su implementación en el año 2018.

En un segundo artículo González recupera la experiencia de la práctica en localidad de la Escuela de Trabajo Social de la Universidad de Costa Rica en el

La Revista Estudios es editada por la Universidad de Costa Rica y se distribuye bajo una Licencia Creative Commons Atribución-NoComercial-CompartirIgual 3.0 Costa Rica. Para más información envíe un mensaje a 


\section{Dossier: V Simposio Internacional y IX Nacional sobre Derechos de la Niñez y la Adolescencia} distrito de Rancho Redondo de Goicoechea de San José, dirigida a la promoción de derechos de niñas, niños y adolescentes. En su presentación el autor hace un recorrido por los enfoques y políticas que han servido de base para la práctica, posterior a ello, narra las buenas experiencias elaboradas por el estudiantado a través del acompañamiento docente y finalmente analiza los retos de los equipos docentes que han trabajado en el distrito.

El tercero de los artículos escrito por Vindas, Briceño, Mc Quiddy, Watson, Garro, Mairena e Hidalgo, quienes participan en los Centros Infantiles Universitarios de la Universidad de Costa Rica muestra sus experiencias en la formación de la primera infancia. En el documento se expresa la experiencia de 40 años en la atención de las niñas y los niños menores de 6 años en relación con los procesos de adaptación, así como el de sus familias.

El artículo cuarto de este dossier fue escrito por la investigadora Marín-Arias. El documento refiere a la promoción de la lactancia materna y a la alimentación del bebé en la comunidad a partir de la experiencia del proyecto Promoción de la lactancia materna y alimentación del niño y la niña menor de 1 año en la comunidad (PROLAMANCO), del Instituto de Investigaciones en Salud (INISA) de la Universidad de Costa Rica. La autora señala que, a pesar de la evidencia científica sobre la importancia de la lactancia materna, esta importante forma de alimentación es poco incentivada en Costa Rica. En su texto muestra resultados de su proyecto en esta materia.

El quinto artículo escrito por González y Sáenz trata sobre la crianza respetuosa centrada en las niñas y los niños. El texto se basa en la experiencia ejecutada desde la fundación PANIAMOR en el posicionamiento del Enfoque de Crianza Respetuosa y su Modelo Somos Familia como forma para acompañar a las familias, promoviendo el desarrollo de competencias parentales y una crianza centrada en las niñas y los niños.

\section{(c) (i) (2)}

La Revista Estudios es editada por la Universidad de Costa Rica y se distribuye bajo una Licencia Creative Commons Atribución-NoComercial-CompartirIgual 3.0 Costa Rica. Para más información envíe un mensaje a 
Dossier: V Simposio Internacional y IX Nacional sobre Derechos de la Niñez y la Adolescencia

El sexto de los artículos a cargo de Olivas se ocupa del desarrollo y bienestar infantil relacional. La autora señala que el documento se deriva de su investigación doctoral cuyo objetivo es identificar los tipos de relaciones en red y la acción colectiva que configuran el desarrollo y bienestar infantil a partir del enfoque relacional.

El último de los artículos presentado en este dossier fue escrito por la autora Jaime, el documento trata sobre la las tendencias y los retos actuales en la evaluación de las dificultades del desarrollo infantil. La autora señala que el documento es una reflexión sobre las dificultades más frecuentes en las infancias. Dentro de los retos identificados es planteado la necesidad de mantener una posición desde el desconocimiento en el saber de la infancia, lo cual en términos de la autora puede permitir la inclusión de la singularidad de las niñas y los niños.

A partir de lo presentado, desde el Programa PRIDENA en conjunto con la Revista Estudios se desea que este dossier derivado del V Simposio Internacional y IX Nacional sobre Derechos de la Niñez y la Adolescencia, resulte de interés para la comunidad universitaria pero especialmente se constituya en un aporte más para las personas que trabajan desde el plano de los derechos de niñas, niños y adolescentes.

Milton Ariel Brenes Rodríguez Programa PRIDENA Universidad de Costa Rica, Costa Rica milton.brenesrodriguez@ucr.ac.cr https://orcid.org/0000-0001-8591-057X

\footnotetext{
(c) (i) (2) (2)

La Revista Estudios es editada por la Universidad de Costa Rica y se distribuye bajo una Licencia Creative Commons Atribución-NoComercial-CompartirIgual 3.0 Costa Rica. Para más información envíe un mensaje a revistaestudios.eeg@ucr.ac.cr.
} 